\title{
Drained cyclic behaviour of loose Dogs Bay sand
}

\author{
S. LÓPEZ-QUEROL* and M. R. COOP $†$
}

\begin{abstract}
The results of drained cyclic triaxial tests performed on Dogs Bay sand (a carbonate sand) are discussed in this paper. For this sand it has been previously demonstrated that the critical state exists and is unique. The relationship between volumetric strains due to cyclic loading and the critical state of this material under monotonic conditions is explored here. Drained cyclic tests on loose samples have been carried out, applying different amplitudes of cyclic loading for samples that generally have initial states on the wet side of critical. The trends of behaviour are summarised, pointing out the relationship between initial state parameter, amplitude of cyclic loading and final change in the state parameter at equilibrium. Experimental evidence is also given to demonstrate that the sand has a memory of the volumetric strain that has previously occurred when different patterns of cyclic loading are consecutively applied and equilibrium has not been reached.
\end{abstract}

KEYWORDS: calcareous soils; compaction; dynamics; sands
La présente communication présente des résultats d'essais triaxiaux cycliques drainés, effectués sur du sable de Dogs Bay (un sable carbonaté). On avait déjà démontré, pour ce sable, l'existence d'un état critique unique. On examine ici les relations entre les contraintes volumétriques, découlant de charges cycliques, et l'état critique de ce matériau en présence de conditions monotones. On a procédé à des essais cycliques drainés sur des échantillons en vrac, en appliquant différentes amplitudes de charges cycliques pour des échantillons qui présentent généralement des états initiaux à tendance mouillée relativement à l'état critique. On y résume les tendances de comportements, en soulignant les rapports entre le paramètre d'état initial, l'amplitude des charges cycliques, et le changement final du paramètre d'état à l'équilibre. On présente également des éléments de preuves expérimentales permettant de démontrer que le sable mémorise les contraintes volumétriques survenues précédemment, lors de l'application consécutive de formes de charges cycliques, et l'équilibre n'ayant pas été atteint.

\section{INTRODUCTION}

Although the critical state framework for monotonic loading was first developed for clays (Schofield \& Wroth, 1968; Atkinson \& Bransby, 1978; Wood, 1990), more recently this approach has been further investigated for sands (Been \& Jefferies, 1985; Been et al., 1991; Coop \& Lee, 1993; Jovicic \& Coop, 1997; Jefferies \& Been, 2000). For several types of sand, Coop \& Lee (1993) found that, for higher stresses, critical states can be represented in the $v-\ln p^{\prime}$ plane as a straight line, named the critical state line, CSL (where $v$ and $p^{\prime}$ denote the specific volume and mean normal effective stress respectively), and that this is parallel to the normal compression line, NCL, which is defined as the line to which all isotropic compression paths converge (Fig. 1; Coop \& Lee, 1993). Some authors, instead of a CSL, have obtained a critical state zone for sands, because of the scatter in the final specific volumes or, in the opinion of others, an incorrect interpretation of 'pseudo' critical states or quasi-steady states as critical states (e.g. Konrad, 1988; Wood, 1990). At lower stress levels the CSLs curve towards a horizontal asymptote (e.g. Lee \& Seed, 1967; Been et al., 1991; Verdugo \& Ishihara, 1996), but Coop (1999) and Klotz \& Coop (2002) suggested that determining the exact location of the CSL at lower pressures was often difficult, first because very large strains of up to $40 \%$ are required to reach critical states for sands, and in some reported cases the tests finished at strain levels of around $20 \%$, which might be insufficient to reach a true critical state. Second, they found that strain localisation was a severe

Manuscript received 19 August 2008; revised manuscript accepted 16 August 2011. Published online ahead of print 24 November 2011.

Discussion on this paper closes on 1 September 2012, for further details see p. ii.

* Department of Civil Engineering, Universidad de Castilla La Mancha, Ciudad Real, Spain.

$\dagger$ Department of Building and Construction, City University of Hong Kong. problem at lower stress levels when trying to identify critical state volumes.

The behaviour of sands under cyclic loading has been widely investigated by means of cyclic simple shear, triaxial and resonant column tests under both drained and undrained conditions (e.g. Silver \& Seed, 1971; Seed \& Silver, 1972; Youd, 1972; Arulmoli et al., 1992; Wijewickreme et al., 2005). This research identified the main factors controlling dynamic sand behaviour, but a critical state framework has generally not been as widely used for explaining cyclic sand behaviour as for monotonic conditions. Although various researchers have not found a relationship between the final volumetric strain and the initial state (Wichtmann et al., 2005), some others, after several attempts, have been successful in finding correlations between undrained cyclic behaviour and critical states (Castro, 1969; Alarcón-Guzmán et al., 1988; Konrad, 1993). However, for a complete framework, the behaviour of sand cycled from states on the NCL should be included, and since this typically involves high pressures, it is technically difficult. Nevertheless, an investigation of the undrained cyclic behaviour of a carbonate sand from states on the NCL was made by Qadimi \& Coop (2007) using the same sand that has been tested here, and this showed that the data could be simply normalised into a uniform pattern of behaviour using a critical state framework similar to that which might apply to monotonic loading.

On the other hand, drained cyclic behaviour has not been clearly investigated using a critical state approach, even if it is well established that the main factors controlling the volumetric strains (densification) are the initial relative density, the amplitude of cyclic shear strain, the effective confining stress, and the number of cycles (Ko \& Scott, 1967; Silver \& Seed, 1971; Seed \& Silver, 1972). It has been observed that if the number of cycles is high enough, the final amount of densification reaches a constant value that can be interpreted as a 'dynamic' critical state (Youd, 1972), which is dependent on the test conditions, but the relationship between these steady equilibrium values and the 


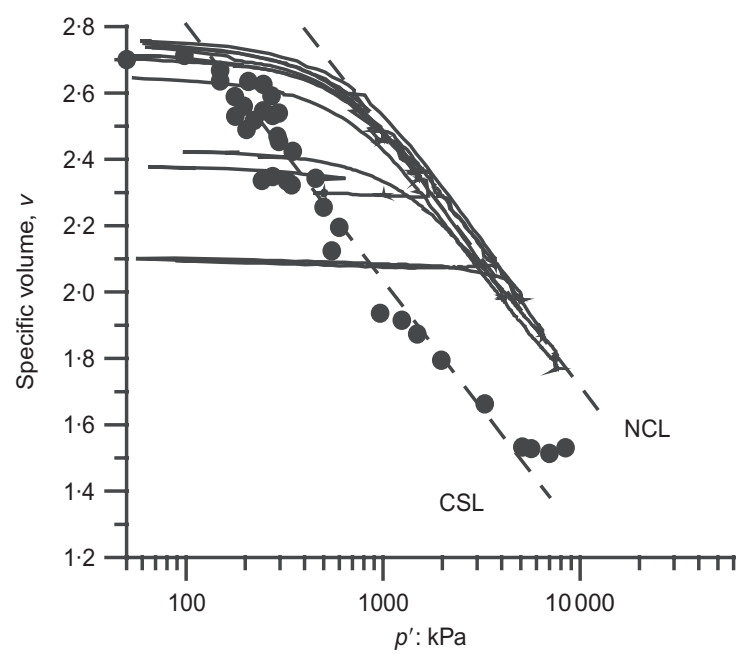

(a)

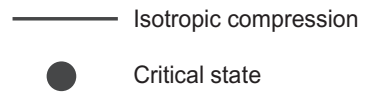

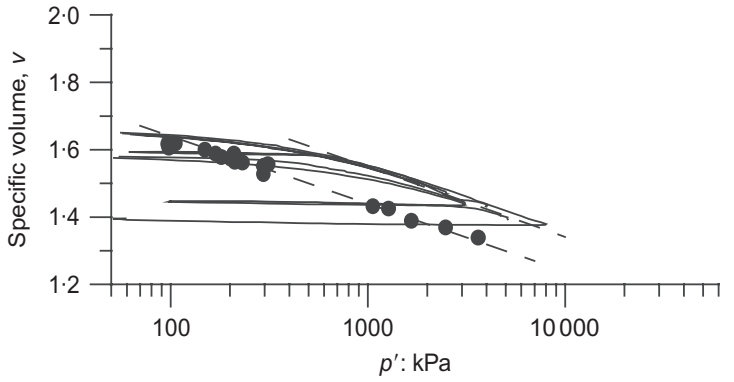

(b)

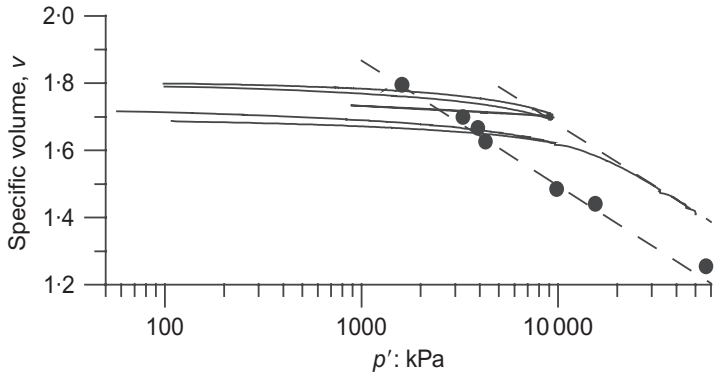

(c)

Fig. 1. Critical state lines (CSL) and normal compression lines (NCL) for three different sands (Coop \& Lee, 1993): (a) Dogs Bay sand; (b) decomposed granite; (c) Ham River sand

critical states under monotonic conditions are still far from clear. On the other hand, some authors have pointed out the influence of the cyclic preloading history on the final amount of densification in drained cyclic tests by means of purely empirical approaches (Wichtmann \& Triantafyllidis, 2004a, 2004b), and in some other cases try to explain the volumetric strain memory of the sand by means of energy and/or fabric considerations (Chang \& Whitman, 1988). Experimental evidence of this in the literature is scarce, and the order of application of cyclic loading stages with different shear strain amplitudes has not been explored.

In this paper the results of drained cyclic triaxial tests on Dogs Bay sand are presented. This material, which is a carbonate sand, has been widely analysed under monotonic loading (Coop, 1990); one key advantage of using it is that the linear part of its CSL is reached at stress levels that are lower than for quartzitic sands, because of the influence that particle breakage has in the location of this line in the $v-\ln p^{\prime}$ plane. This allows cyclic triaxial tests to be performed from states on the wet side of the CSL and over a range of stresses where the CSL is linear in the $v-\ln p^{\prime}$ plane using fairly standard apparatus with a modest pressure capacity. Investigating the behaviour of the sand in the range of stresses where the CSL is linear can be seen as a simple first step to understand what might happen at lower stresses as the CSL curves.

The paper begins by describing the properties of the sand used, after which the apparatus, the setting-up process for the samples, and the tests performed are described. The results are then summarised, highlighting the experimental evidence for the volumetric strain memory of the sand under cyclic loading, and exploring the relationship between critical states under monotonic loading and the drained cyclic behaviour.

\section{SAND DESCRIPTION AND TESTING PROCEDURES}

Dogs Bay sand is a typical biogenic carbonate sand from a beach on the west coast of the Republic of Ireland. It consists mainly of mollusc and foraminifera shells, and so its calcium carbonate content is relatively high at around 88-94\% (Houlsby et al., 1988). Its natural grading curve, given in Fig. 2, shows that it is a poorly graded sand, with $D_{50}$ of about $0.2 \mathrm{~mm}$. Some index properties of this sand and parameters that control its behaviour under monotonic loading, reported by Coop (1990) and Qadimi (2005), are also provided in Table 1. As can be seen in Fig. 1, the NCL and CSL of Dogs Bay sand are significantly steeper than

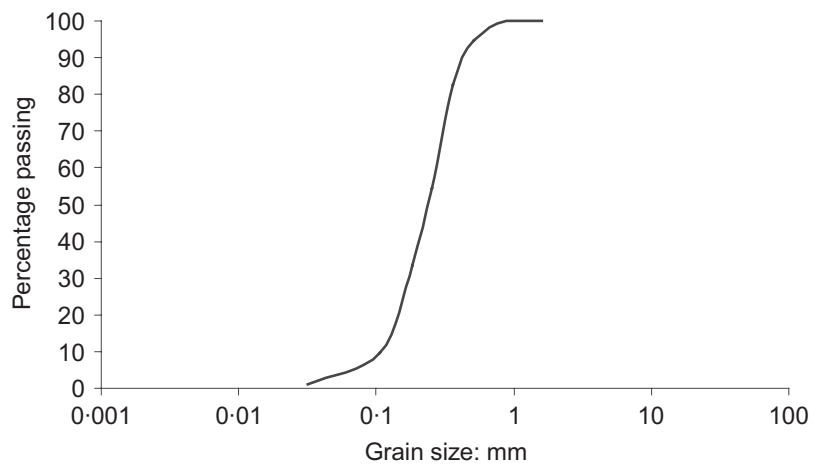

Fig. 2. Natural grading curve of Dogs Bay sand (after Qadimi, 2005)

Table 1. Index properties and parameters of Dogs Bay sand (Coop, 1990; Qadimi, 2005)

\begin{tabular}{l|c}
\hline Property & Value \\
\hline$D_{50}: \mathrm{mm}$ & $0 \cdot 20$ \\
$D_{10}: \mathrm{mm}$ & $0 \cdot 15$ \\
$U_{\mathrm{c}}=D_{60} / D_{10}$ & $1 \cdot 47$ \\
$G_{\mathrm{s}}: \mathrm{kN} / \mathrm{m}^{3}$ & $26 \cdot 56$ \\
$e_{\max }$ & $1 \cdot 84$ \\
$e_{\min }$ & $1 \cdot 37$ \\
$M_{\mathrm{c}}$ & $1 \cdot 65$ \\
$\phi_{\mathrm{c}}^{\prime}$ & $40 \cdot 3$ \\
$\lambda$ & $0 \cdot 30$ \\
$\kappa$ & $0 \cdot 0075$ \\
$N$ & $4 \cdot 47$ \\
$\lambda / \kappa$ & 40 \\
$N-\Gamma$ & $0 \cdot 45$ \\
$K_{0}$ & $0 \cdot 51$ \\
\hline
\end{tabular}


those of other, more typically encountered sands, such as the Ham River sand, which is quartzitic. However, there is extensive research (e.g. Coop \& Lee, 1993, Jovicic \& Coop, 1997, Klotz \& Coop, 2001, 2002) that shows that the mechanics of this carbonate sand, both in monotonic laboratory tests and in the behaviour of piles, is fundamentally no different from that of other sands. For example, stressdilatancy data for the sand were investigated by Coop (1990) (Fig. 3), and the data are similar to those of other sands, with samples on the dry side of critical dilating giving peak strengths (tests 10 and 11), whereas those on the wet side (tests $\mathrm{H}$ and $\mathrm{L}$ ) compress to their critical state with no peak strength. Probably the most unusual feature of the sand is the very high specific volumes that it has, because of the angularity of its particles, which cause the NCL to be encountered at relatively modest stress levels (Fig. 1) in compression. This causes the state of the sand to move onto the wet side of the CSL at lower stresses than, for example, a quartzitic sand.

The values of $\lambda$ and $N$ in Table 1 (the slope and intercept at $p^{\prime}=1 \mathrm{kPa}$ of the NCL in the $v-\ln p^{\prime}$ plane) are those determined by Qadimi \& Coop (2007), which differ slightly from those previously reported by Coop (1990), because in the determination of the NCL these authors used slower rates of isotropic compression. Although Qadimi did not report a recalculated value of $\Gamma$ (the intercept of the CSL at $p^{\prime}=1 \mathrm{kPa}$ in the $v-\ln p^{\prime}$ plane), in the present research both lines (the NCL and CSL) have been considered parallel, and the spacing between them, $N-\Gamma$, has been assumed to be independent of the rate of loading with a value equal to that reported by Coop (1990), which is also given in Table 1 .

Cyclic triaxial tests were carried out in a computercontrolled hydraulic triaxial apparatus with a maximum cell pressure capacity of $1800 \mathrm{kPa}$, designed for samples $38 \mathrm{~mm}$ in diameter and a height to diameter ratio of $2: 1$. The three pressure controllers for ram, back and cell pressures were air-regulated. The air pressure was supplied by a main compressor at $800 \mathrm{kPa}$, and transferred to water pressure through air/water interfaces. In the case of the back-pressure, this interface was an Imperial College volume gauge, which allows the volume of water coming out from the sample during the tests to be recorded. The axial strains were measured both externally with an LVDT mounted outside the pressure chamber and internally by two miniature LVDTs that were directly attached to the membrane (Cuccovillo \& Coop, 1997). In all the tests, a rubber suction cap was used to connect the sample top platen to the internal load cell, thereby allowing negative deviatoric stresses to be applied. This suction cap also helps in reducing the errors related to

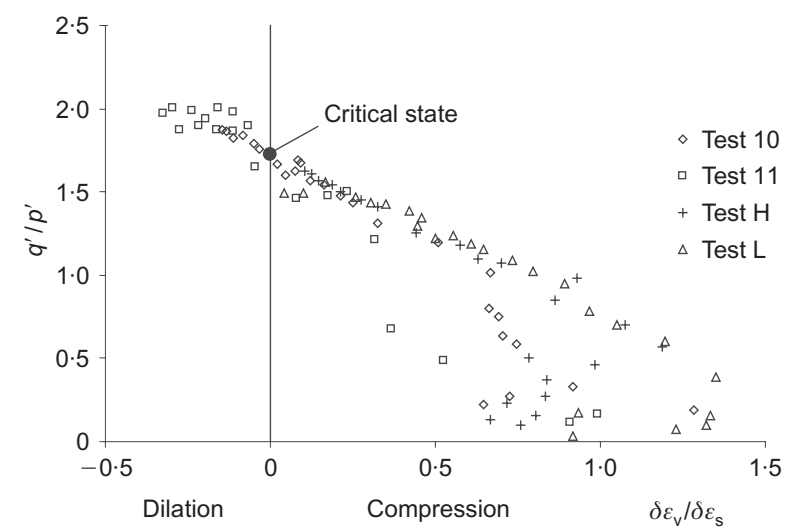

Fig. 3. Stress-dilatancy data for monotonic drained tests on Dogs Bay sand (after Coop, 1990) seating and tilting between load cell and top platen (Atkinson \& Evans, 1985).

The sand was tested with its natural grading, given in Fig. 2. In order to ensure that this was repeatable, for each test it was reconstituted from previously sieved sand. To aid with saturation, before setting up the samples the sand was submerged in distilled water and put under a vacuum for $45 \mathrm{~min}$. The samples were then created by pluviation, placing the sand with a small spoon directly into the waterfilled membrane held within a mould on the triaxial pedestal, taking care to maintain the sand under water at all times.

After pluviation, the samples were held on the platen under a negative pore pressure of about $20 \mathrm{kPa}$ while the dimensions were measured. The initial specific volumes of the samples were determined at the beginning by calculating their initial dry densities, and also from the final water content at the end of the test, accounting for the total volumetric strain experienced by the sample during the test. In all cases, the two determinations differed by less than $2 \%$. The initial specific volumes of the samples given in Table 2, however, are those based solely on the final water content, which was considered more accurate.

The samples were first saturated under an effective stress equal to that when the sample dimensions were measured, and a back-pressure of $200-300 \mathrm{kPa}$ was applied until a $B$ value of at least 0.98 was achieved. After saturation the sample was connected to the internal load cell using the suction cap, and then isotropic compression was applied at a rate of $20 \mathrm{kPa} / \mathrm{h}$ until the desired confining stress was reached. No cyclic loading was applied until the volumetric strain due to creep was stable, with values smaller than $0.001 \% / \mathrm{h}$

Cyclic loading stages were then applied from the isotropic initial condition. The cyclic loading was step shaped, with a loading sequence of $22.5 \mathrm{~s}$ at $q_{\max }, 22.5 \mathrm{~s}$ at $q=0,22.5 \mathrm{~s}$ at $q_{\text {min }}$, and finally $22.5 \mathrm{~s}$ at $q=0$. The $90 \mathrm{~s}$ total period was the fastest that could be accurately followed by the stress control system. In addition, it was slow enough to ensure that the stresses were homogeneous within the sample, with no undissipated pore pressures. On application of the load steps, the volumetric strain often took $10 \mathrm{~s}$ or more to stabilise. Since the step length was only $22.5 \mathrm{~s}$, it is clear that a much higher frequency could not have been applied with this system without causing partially incomplete drainage, although it is not known to what extent the response time of the volumetric strain was the result of the consolidation characteristics of the soil, the drainage system used, or the response time of the volume gauge used to measure the strain. Qadimi \& Coop (2007) demonstrated that within one order of magnitude of period, there was no significant influence of the period on the undrained behaviour of Dogs Bay sand, or from using the step-shaped loading sequence as compared with a sinusoidal one. It has therefore been assumed in this research that these influences are also small for drained tests.

\section{SUMMARY OF THE TESTS CONDUCTED}

Table 2 and Fig. 4 provide a summary of the tests conducted. Eight sand samples, with different initial relative densities, were tested. After isotropic compression, each one was subjected to different patterns of cyclic loading. The number of cycles in each case was variable; in some a final state very close to equilibrium of volumetric strain was obtained, whereas in other cases it was not. At the end of each cyclic loading stage, the rate of change of specific volume (equal to change of state parameter) with the number of cycles, $N$, has been computed and is included in Table 
Table 2. Summary of all the conducted tests

\begin{tabular}{|c|c|c|c|c|c|c|c|}
\hline Test & $v_{0}$ & $v_{\mathrm{f}}$ & $p_{0}^{\prime}: \mathrm{kPa}$ & $\beta$ & $N^{\circ}$ : cycles & Final rate $(\Delta v / \Delta \log N=\Delta \psi / \Delta \log N)$ & Equilibrium \\
\hline T5 cyc1 & $2 \cdot 3544$ & $2 \cdot 3543$ & 500 & 0.05 & 88 & $-5 \cdot 14 \times 10^{-5}$ & Yes \\
\hline T5сус 2 & $2 \cdot 3543$ & $2 \cdot 3528$ & 500 & $0 \cdot 1$ & 288 & $-1.31 \times 10^{-3}$ & Yes \\
\hline T5 cyc3 & $2 \cdot 3528$ & $2 \cdot 3346$ & 500 & $0 \cdot 2$ & 300 & $-4.12 \times 10^{-3}$ & No \\
\hline T5 сус 4 & $2 \cdot 3346$ & $2 \cdot 3137$ & 500 & $0 \cdot 3$ & 300 & $-1.59 \times 10^{-2}$ & No \\
\hline T5 cyc5 & $2 \cdot 3136$ & $2 \cdot 3127$ & 500 & $0 \cdot 2$ & 500 & $-9 \cdot 14 \times 10^{-4}$ & Yes \\
\hline T5сус6 & $2 \cdot 3126$ & $2 \cdot 3065$ & 500 & $0 \cdot 3$ & 830 & $-6.51 \times 10^{-3}$ & No \\
\hline T5 cyc 7 & $2 \cdot 3063$ & $2 \cdot 3061$ & 500 & $0 \cdot 1$ & 600 & $1.15 \times 10^{-3}$ & Yes \\
\hline Т5 сус 8 & $2 \cdot 3067$ & $2 \cdot 3092$ & 500 & $0 \cdot 3$ & 200 & $8.53 \times 10^{-4}$ & Yes \\
\hline Т5сус9 & $2 \cdot 3091$ & $2 \cdot 3099$ & 500 & $0 \cdot 1$ & 600 & $5.12 \times 10^{-4}$ & Yes \\
\hline T5 cyc 10 & $2 \cdot 3138$ & $2 \cdot 3139$ & 300 & $0 \cdot 1$ & 220 & $1.18 \times 10^{-3}$ & Yes \\
\hline T5 cyc 11 & $2 \cdot 3139$ & $2 \cdot 3139$ & 300 & $0 \cdot 2$ & 500 & $0.00 \times 10^{+0}$ & Yes \\
\hline $\mathrm{T} 5 \mathrm{cyc} 12$ & $2 \cdot 3223$ & $2 \cdot 3235$ & 100 & $0 \cdot 2$ & 600 & $6.61 \times 10^{-5}$ & Yes \\
\hline T6cyc1 & $2 \cdot 1354$ & $2 \cdot 1072$ & 600 & $0 \cdot 3$ & 730 & $-3 \cdot 16 \times 10^{-3}$ & No \\
\hline T6 cyc2 & $2 \cdot 1071$ & $2 \cdot 1072$ & 600 & $0 \cdot 2$ & 200 & $0.00 \times 10^{+0}$ & Yes \\
\hline T6cyc3 & $2 \cdot 1047$ & $2 \cdot 1033$ & 800 & $0 \cdot 2$ & 170 & $-2.23 \times 10^{-3}$ & No \\
\hline T6сус4 & $2 \cdot 1034$ & $2 \cdot 1043$ & 800 & $0 \cdot 1$ & 400 & $0.00 \times 10^{+0}$ & Yes \\
\hline T6сyc5 & $2 \cdot 1038$ & $2 \cdot 1035$ & 800 & $0 \cdot 2$ & 270 & $-1.10 \times 10^{-3}$ & Yes \\
\hline Т6сус6 & $2 \cdot 1034$ & $2 \cdot 0990$ & 800 & $0 \cdot 3$ & 600 & $-5.42 \times 10^{-3}$ & No \\
\hline T6cyc7 & 2.0990 & 2.0990 & 800 & $0 \cdot 1$ & 160 & $4.99 \times 10^{-5}$ & Yes \\
\hline T8cyc1 & $2 \cdot 2668$ & $2 \cdot 2666$ & 200 & 0.05 & 88 & $-2.81 \times 10^{-4}$ & Yes \\
\hline T8сус2 & $2 \cdot 2667$ & 2.2655 & 200 & $0 \cdot 1$ & 288 & $-9.02 \times 10^{-4}$ & Yes \\
\hline T8cyc3 & 2.2656 & 2.2593 & 200 & $0 \cdot 2$ & 300 & $-2.34 \times 10^{-3}$ & No \\
\hline T8cyc4 & $2 \cdot 2592$ & $2 \cdot 2496$ & 200 & $0 \cdot 3$ & 300 & $-7.78 \times 10^{-3}$ & No \\
\hline T8cyc5 & $2 \cdot 2490$ & $2 \cdot 2482$ & 200 & $0 \cdot 2$ & 500 & $-3.73 \times 10^{-4}$ & Yes \\
\hline T8cyc6 & $2 \cdot 2481$ & $2 \cdot 2466$ & 200 & $0 \cdot 3$ & 830 & $-1.73 \times 10^{-3}$ & Yes \\
\hline T8cyc7 & $2 \cdot 2465$ & $2 \cdot 2468$ & 200 & $0 \cdot 1$ & 600 & $-3.00 \times 10^{-4}$ & Yes \\
\hline T8cyc8 & $2 \cdot 2465$ & $2 \cdot 2467$ & 200 & 0.05 & 883 & $2.22 \times 10^{-4}$ & Yes \\
\hline T10cyc1 & 2.4397 & 2.4389 & 500 & 0.05 & 88 & $-2.57 \times 10^{-3}$ & No \\
\hline $\mathrm{T} 10 \mathrm{cyc} 2$ & 2.4377 & $2 \cdot 4345$ & 500 & $0 \cdot 1$ & 288 & $-4.27 \times 10^{-3}$ & No \\
\hline T10cyc 3 & $2 \cdot 4344$ & $2 \cdot 4132$ & 500 & $0 \cdot 2$ & 300 & $-9.63 \times 10^{-3}$ & No \\
\hline T10cyc4 & $2 \cdot 4125$ & $2 \cdot 3923$ & 500 & $0 \cdot 3$ & 300 & $-1.13 \times 10^{-2}$ & No \\
\hline T10cyc5 & $2 \cdot 3922$ & $2 \cdot 3902$ & 500 & $0 \cdot 2$ & 500 & $-3 \cdot 18 \times 10^{-3}$ & No \\
\hline T10cyc6 6 & $2 \cdot 3900$ & $2 \cdot 3868$ & 500 & $0 \cdot 3$ & 830 & $-4.47 \times 10^{-3}$ & No \\
\hline T10cyc 7 & $2 \cdot 3864$ & $2 \cdot 3856$ & 500 & $0 \cdot 1$ & 600 & $-3 \cdot 37 \times 10^{-4}$ & Yes \\
\hline T10cyc 8 & $2 \cdot 3852$ & $2 \cdot 3846$ & 500 & $0 \cdot 3$ & 200 & $-1.32 \times 10^{-3}$ & Yes \\
\hline T10cyc9 & $2 \cdot 3846$ & $2 \cdot 3840$ & 500 & $0 \cdot 1$ & 600 & $-1.09 \times 10^{-3}$ & Yes \\
\hline T11cyc1 & $2 \cdot 2784$ & $2 \cdot 2765$ & 200 & 0.05 & 88 & $-2.16 \times 10^{-3}$ & No \\
\hline $\mathrm{T} 11 \mathrm{cyc} 2$ & $2 \cdot 2779$ & $2 \cdot 2773$ & 200 & $0 \cdot 1$ & 288 & $-2 \cdot 13 \times 10^{-3}$ & No \\
\hline T11cyc3 & $2 \cdot 2742$ & $2 \cdot 2697$ & 200 & $0 \cdot 2$ & 300 & $-3 \cdot 81 \times 10^{-3}$ & No \\
\hline T11 cyc4 & 2.2696 & $2 \cdot 2584$ & 200 & $0 \cdot 3$ & 300 & $-4.35 \times 10^{-3}$ & No \\
\hline T11cyc5 & $2 \cdot 2580$ & $2 \cdot 2571$ & 200 & $0 \cdot 2$ & 500 & $-5.49 \times 10^{-4}$ & Yes \\
\hline T11 cyc6 & $2 \cdot 2570$ & $2 \cdot 2546$ & 200 & $0 \cdot 3$ & 830 & $-2.47 \times 10^{-3}$ & No \\
\hline T11 cyc7 & $2 \cdot 2545$ & $2 \cdot 2542$ & 200 & $0 \cdot 1$ & 600 & $-1.91 \times 10^{-3}$ & Yes \\
\hline T11 cyc8 & $2 \cdot 2541$ & 2.2539 & 200 & $0 \cdot 3$ & 200 & $-1.17 \times 10^{-3}$ & Yes \\
\hline T11 cyc9 & 2.2539 & 2.2536 & 200 & $0 \cdot 1$ & 600 & $-3 \cdot 10 \times 10^{-4}$ & Yes \\
\hline $\mathrm{T} 12 \mathrm{cyc} 1$ & $2 \cdot 4191$ & $2 \cdot 4189$ & 200 & 0.05 & 88 & $-4.82 \times 10^{-4}$ & Yes \\
\hline $\mathrm{T} 12 \mathrm{cyc} 2$ & $2 \cdot 4190$ & $2 \cdot 4179$ & 200 & $0 \cdot 1$ & 288 & $-9.73 \times 10^{-4}$ & Yes \\
\hline T12cyc3 & 2.4179 & $2 \cdot 4119$ & 200 & $0 \cdot 2$ & 300 & $-1.81 \times 10^{-3}$ & Yes \\
\hline T12cyc 4 & $2 \cdot 4119$ & $2 \cdot 4001$ & 200 & $0 \cdot 3$ & 300 & $-1.84 \times 10^{-3}$ & Yes \\
\hline T12cyc5 & $2 \cdot 4001$ & $2 \cdot 3996$ & 200 & $0 \cdot 2$ & 500 & $0.00 \times 10^{+0}$ & Yes \\
\hline T12cyc6 & 2.3996 & $2 \cdot 3834$ & 200 & $0 \cdot 3$ & 830 & $1.64 \times 10^{-4}$ & Yes \\
\hline T12cyc7 & $2 \cdot 3606$ & $2 \cdot 3123$ & 500 & $0 \cdot 3$ & 1605 & $1.27 \times 10^{-2}$ & No \\
\hline T12cyc8 & $2 \cdot 3123$ & $2 \cdot 3119$ & 500 & $0 \cdot 2$ & 800 & $5.71 \times 10^{-5}$ & Yes \\
\hline T12cyc9 & $2 \cdot 3116$ & $2 \cdot 3116$ & 500 & $0 \cdot 1$ & 800 & $1.78 \times 10^{-4}$ & Yes \\
\hline T13cyc1 & $2 \cdot 3323$ & $2 \cdot 3239$ & 380 & $0 \cdot 1$ & 3000 & $-7.68 \times 10^{-3}$ & No \\
\hline T13 cyc2 & 2.3239 & $2 \cdot 3225$ & 380 & $0 \cdot 1$ & 900 & $-3.41 \times 10^{-3}$ & No \\
\hline T13 cyc3 & $2 \cdot 3224$ & $2 \cdot 3110$ & 380 & $0 \cdot 2$ & 3000 & $-1.24 \times 10^{-2}$ & No \\
\hline T13сус4 & $2 \cdot 3110$ & $2 \cdot 2951$ & 380 & $0 \cdot 3$ & 2900 & $-1.34 \times 10^{-2}$ & No \\
\hline T14cyc1 & $2 \cdot 3315$ & $2 \cdot 3314$ & 500 & 0.05 & 88 & $-1.20 \times 10^{-4}$ & Yes \\
\hline $\mathrm{T} 14 \mathrm{cyc} 2$ & $2 \cdot 3314$ & $2 \cdot 3264$ & 500 & $0 \cdot 1$ & 1488 & $-4.27 \times 10^{-3}$ & No \\
\hline T14cyc3 & $2 \cdot 3264$ & $2 \cdot 3067$ & 500 & $0 \cdot 2$ & 800 & $-4.56 \times 10^{-3}$ & No \\
\hline T14cyc4 & $2 \cdot 3068$ & $2 \cdot 2825$ & 500 & $0 \cdot 3$ & 1330 & $-6.41 \times 10^{-3}$ & No \\
\hline T14cyc5 & $2 \cdot 2823$ & $2 \cdot 2823$ & 500 & $0 \cdot 2$ & 800 & $-8.93 \times 10^{-4}$ & Yes \\
\hline T14cyc6 & $2 \cdot 2819$ & $2 \cdot 2819$ & 500 & $0 \cdot 1$ & 800 & $-5.66 \times 10^{-4}$ & Yes \\
\hline T14cyc7 & $2 \cdot 2818$ & $2 \cdot 2683$ & 500 & $0 \cdot 4$ & 800 & $-1.65 \times 10^{-2}$ & No \\
\hline T14cyc 8 & $2 \cdot 2665$ & $2 \cdot 2656$ & 500 & $0 \cdot 3$ & 500 & $-1.83 \times 10^{-3}$ & Yes \\
\hline
\end{tabular}




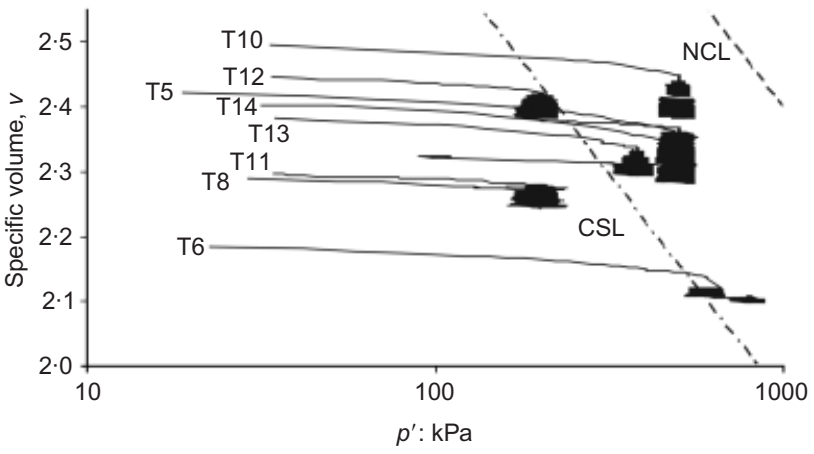

Fig. 4. Summary in the $v-\ln p^{\prime}$ plane of all the drained cyclic triaxial tests performed

2. For sake of clarity in the explanations of several issues discussed in this paper, a linear $N$ axis has been used throughout. However, for computing the final rate of change of specific volume, a logarithmic scale has been used, as is usual for defining equilibrium in similar research (e.g. Vaneekelen \& Potts, 1978; Wichtmann et al., 2005). A reference value of $2 \times 10^{-3}$ (positive or negative) has been selected arbitrarily to determine whether a final equilibrium volume has been reached or not; rates of change smaller than this value would mean an almost negligible change of specific volume, and would have a very small impact in Figs 4 and 12.

It is interesting that some other authors (e.g. Wichtmann et al., 2005) found it difficult to reach equilibrium of the accumulated volumetric strain for drained cyclic loading of quartzitic sands unless very much higher numbers of cycles than used in the present research were applied. However, for the particular case of Dogs Bay sand, an asymptotic trend has been found in all cases at numbers of cycles of the order of $10^{2}-10^{3}$, with a maximum final rate in a test that was intended to reach equilibrium of $1.6 \times 10^{-2}$, which indicates a state very close to equilibrium. Here the approach taken was to use relatively slow cycles, partly through the limitations of the apparatus, but this also ensured that the volumetric strain was in equilibrium at all stages of each cycle. It would not have been practical to reach even one order greater a number of cycles, as each test already lasted typically 20 days. To reach the hundreds of thousands of cycles often used by others implies that a period of only a few seconds must be employed if the tests are to be completed in a realistic time. For the soil used, it could not be guaranteed that complete drainage would then have occurred at every stage of the cycle, and the impact that this might have for this soil on the overall volumetric strain trend is unknown.

The denomination of the cyclic tests follows the scheme Txcycy, where $x$ denotes the number of the test, and $y$ is the number of each cyclic stage. Full details of each test are given in Table 2, including the initial and final specific volumes for each cyclic stage $\left(v_{0}\right.$ and $\left.v_{\mathrm{f}}\right)$, the initial mean normal effective stress $\left(p_{0}^{\prime}\right)$, the amplitude of cyclic loading ( $\beta=\Delta q / p_{0}^{\prime}$, where $\Delta q$ denotes the amplitude of cyclic deviatoric stress), the number of cycles, and whether volumetric equilibrium was reached or not at the end of the cyclic loading. All the tests were conducted on samples that were currently under the maximum $p^{\prime}$ that they had experienced, and although none had actually reached the NCL in the $v-\ln p^{\prime}$ plane, they had states either on the wet side of the CSL or slightly on the dry side. States further to the dry side were avoided, because of possible problems with strain localisation. For the three last stages of test T5 the sample was isotropically unloaded after several stages of cyclic loading at higher stress levels.

As can be seen in Fig. 5, where the specific volume is plotted against the number of cycles for several stages of cyclic loading, in the cyclic tests the volumetric strain typically increases with each cycle (i.e. the sample reduces in volume), with a recoverable component of strain that oscillates around a non-recoverable mean strain, which in turn tends to an asymptotic value as the number of cycles increases. For a given amplitude of cyclic loading, equilibrium is reached when the non-recoverable strain reaches, or at least is very close to, an asymptotic value. The elastic modulus, and hence the recoverable strain, is simply related to the normal effective stress and specific volume. In the following, only the irrecoverable volumetric strain is analysed. In Fig. 4, these tests are represented in the $v-\ln p^{\prime}$ plane, showing both the isotropic compression and the cyclic shearing stages and their positions relative to the CSL and NCL of Dogs Bay sand.

\section{INFLUENCE OF THE ORDER OF APPLICATION OF DIFFERENT $\beta$ VALUE STAGES}

Five samples (tests T5, T8, T10, T11, T12), with different initial specific volumes and effective confining stresses, were each initially subjected to the same seven stages of cyclic loading with different amplitudes, in the same order of application (Table 2). The purpose of these series of tests was to identify the relationship between the initial state parameter $\psi_{0}$ (as defined in Fig. 6) and the change in specific volume. In each stage of these tests a fixed number of cycles was applied for each $\beta$, but for the earlier stages these cycles were not sufficient for the equilibrium volume to be reached, so that the effect of applying cycles of other $\beta$ values and then returning to the former value could be explored. To investigate the influence of the order of application of the different stages, sample T14 was subjected to the same total number of cycles for each $\beta$, but in this case

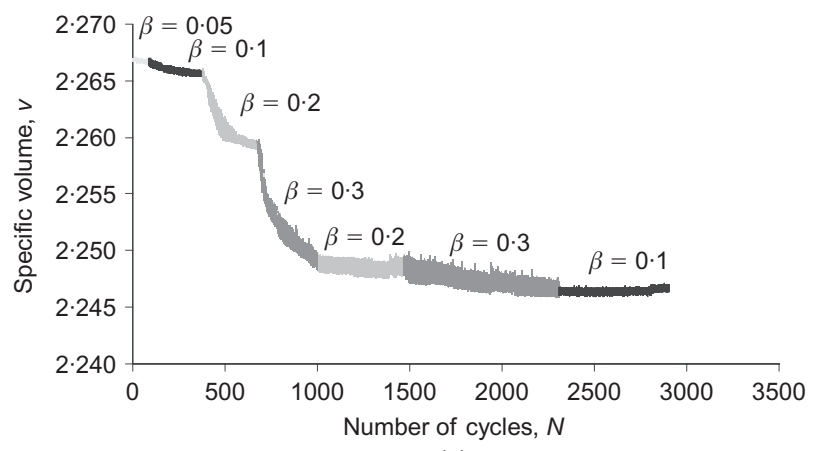

(a)

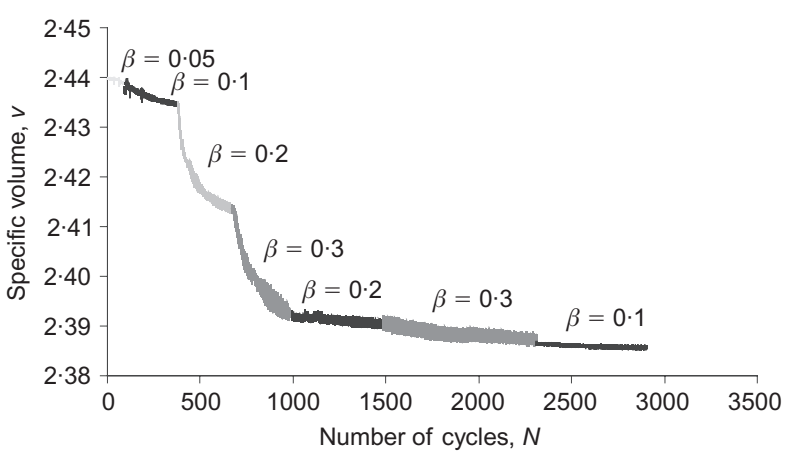

(b)

Fig. 5. The first seven cyclic loading stages of: (a) sample T8; (b) sample T10 


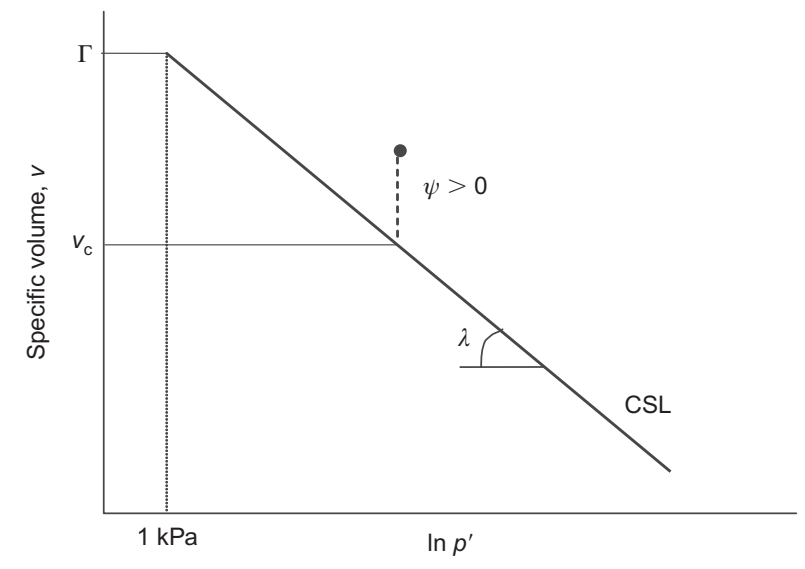

Fig. 6. Definition of state parameter, $\psi$ (Been \& Jefferies, 1985)

applied all in one stage and with each stage having a greater $\beta$ than the previous one, so that each stage typically reached equilibrium before the test proceeded to the next $\beta$.

Figure 5 shows the truncated results for tests T8 and T10 (only the first seven cyclic loading stages of each test are presented in these graphs), in terms of specific volume plotted against the number of cycles. In spite of the different initial conditions, with initial specific volumes of $2 \cdot 27$ and 2.44 and initial effective stresses of $200 \mathrm{kPa}$ and $500 \mathrm{kPa}$ respectively, and so different total amount of volumetric strain in the two tests, the similarity of the responses is selfevident.

Analysing similar graphs for all the tests, a continuity of the paths with the same $\beta$ value was found. Thus Fig. 7 shows the results for the first seven cyclic loading stages on sample T5, not in the order in which they were applied but with all the stages of the same $\beta$ plotted together, and with $\beta$ increasing from $0 \cdot 05$ to $0 \cdot 3$. To facilitate comparison between tests with slightly different initial specific volumes, the $y$-axis used here is $1-\Delta \psi$, where $\Delta \psi$ is the change of state parameter. The value of $1-\Delta \psi$ in Fig. 7 has also been calculated cumulatively from one stage to the next. From an inspection of this figure it is clear that there is a continuity between the responses with the same $\beta$ value. This is particularly noticeable, for example, for T5cyc2 and T5cyc7, each having $\beta=0 \cdot 1$, but with stages of larger $\beta$ values in between. The same applies to paths T5cyc3 and T5cyc5, with $\beta=0 \cdot 2$, which had stage T5cyc4, with $\beta=0 \cdot 3$, between them. It is clear in each case that the sample retains a 'memory' of the previous loading stage with the same $\beta$, which is unaffected by intervening stages of other $\beta$ values.

Figure 8 shows the results of test T14. In this case, in the first four cyclic loading stages, the same number of cycles as in the first nine stages of T5 were applied, but all of them

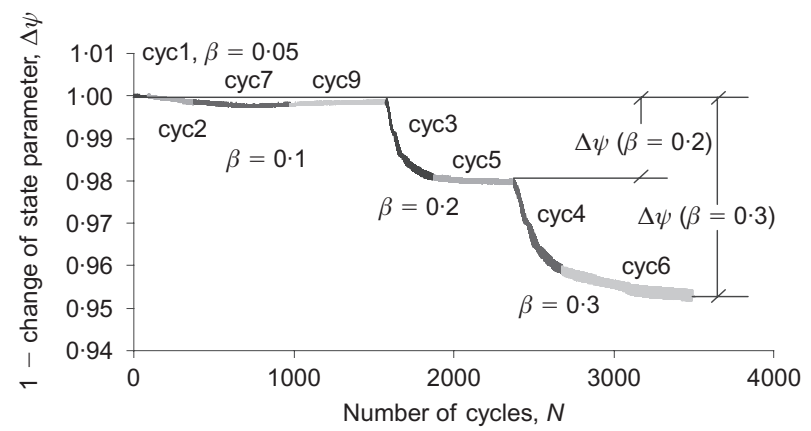

Fig. 7. The first seven stages of cyclic loading for sample T5, reordered to plot all the data for the same $\beta$ value together, and in sequence of increasing $\beta$

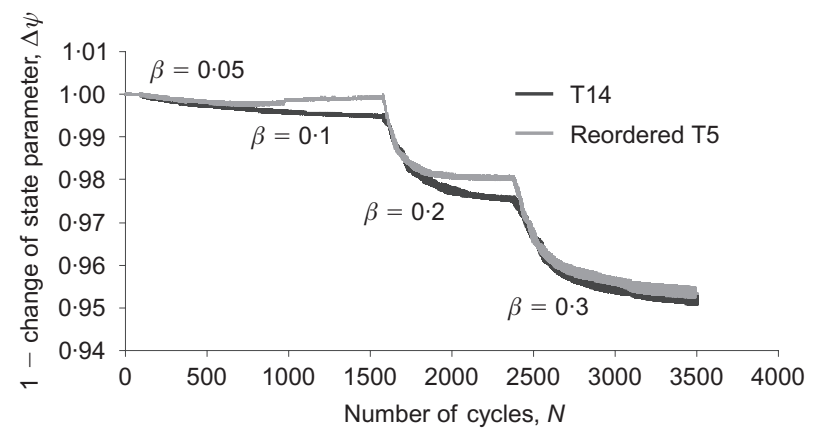

Fig. 8. Comparison between the first four stages of cyclic loading on $\mathrm{T} 14$ and the reordered set of data for tests T5

in a single stage for each $\beta$ value, and applying successively larger $\beta$ values. A comparison is made with the data for sample T5 after being reordered, since small differences in the initial specific volume of both sets of data have essentially been normalised, as discussed above, by plotting $1-\Delta \psi$. Samples T5 and T14 had fairly similar initial state parameters $(+0 \cdot 199$ and $+0 \cdot 176$ respectively), so that the changes of specific volume for all the $\beta$ values were similar for the two samples. The two tests show quite similar responses, again emphasising that continuity of change of specific volume response is maintained for any $\beta$ value, despite intervening stages of different $\beta$ value.

This type of continuity between the responses with the same $\beta$ value has been found in all cases, with the exception of those in which the intervening stage involved a higher $\beta$ value, and where equilibrium had been reached for that stage. Provided equilibrium was not reached in the intervening stage, it did not matter whether that stage had a higher or lower $\beta$ value than those before and after. So, for example, for sample T14 there is no continuity between T14cyc2 and T14cyc6, with $\beta=0 \cdot 1$ (Fig. 9(a)), because equilibrium for $\beta=0.2$ had been reached in T14cyc5. A distinct discontinuity or break can therefore be seen in the gradient of the data where the two stages have been joined.

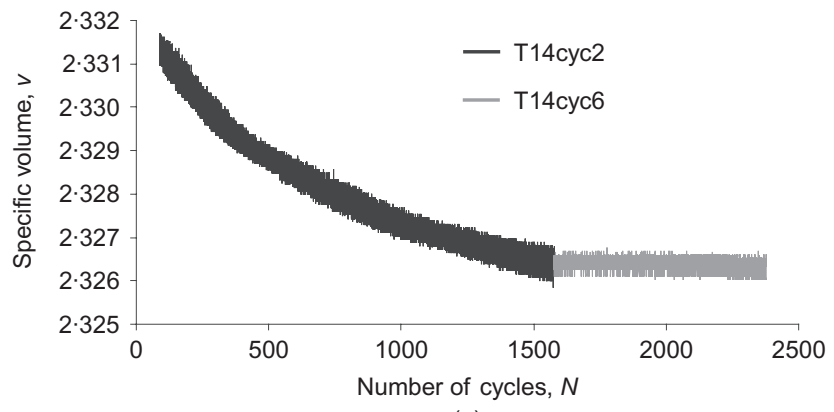

(a)

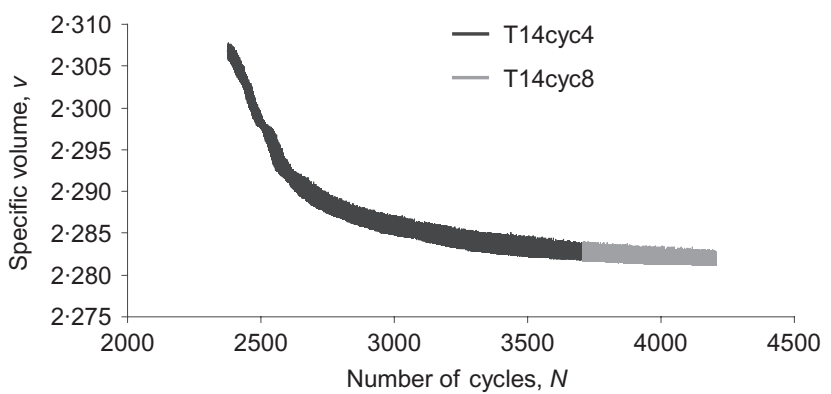

(b)

Fig. 9. Loading stages for different $\beta$ values for sample T14: (a) response for stages with $\beta=0 \cdot 1$; (b) response for stages with $\boldsymbol{\beta}=\mathbf{0} \cdot \mathbf{3}$ 
However, for the same sample, there is good continuity between T14cyc4 and T14cyc8, with $\beta=0 \cdot 3$ (Fig. 9(b)), even though 800 cycles with $\beta=0 \cdot 4$ had been applied in between, but without reaching equilibrium.

For sample T12, after the common stages of cyclic loading under an initial effective stress of $p_{0}^{\prime}=200 \mathrm{kPa}$, the sample was isotropically compressed to a new effective confining pressure of $500 \mathrm{kPa}$, to erase any anisotropy that might have developed in the sample through cyclic axial loading. It was then subjected to three new stages of cyclic loading with $\beta=0.3,0.2$ and $0 \cdot 1$ respectively. The results of this series of tests are given in Fig. 10, where it is clear that, after reaching equilibrium for the first stage $(\beta=0 \cdot 3)$, the subsequent loading stages did not produce any further volumetric strain. If the order of application of cyclic loading had been the opposite, that is, increasing from $\beta=0 \cdot 1$ to $\beta=0 \cdot 3$, as for sample T14 (Fig. 8), equilibrium for each $\beta$ value might have been reached, but the final change of specific volume would have been the same, according to the experimental results reported by Kaggwa et al. (1991). It can therefore be concluded that if a sample reaches equilibrium under a particular $\beta$ value, it does not matter whether other stages of lower $\beta$ value are applied either before or after, as the final volumetric strain should be the same. Thus the key factor that controls the volumetric strain behaviour of the sample should be its initial stress-volume state, prior to applying any cyclic loading, rather than the state immediately prior to applying a stage of any particular $\beta$ value. This initial condition can be conveniently expressed in terms of the initial state parameter, $\psi_{0}$, as defined in Fig. 6.

\section{INFLUENCE OF AN INTERRUPTION IN A CYCLIC LOADING STAGE}

Figure 11 shows the effect of interruptions of $24 \mathrm{~h}$ between two stages with the same $\beta$ value for samples T12 and T13. In the first case (T12, Fig. 11(a)), the interruption happened when the equilibrium of specific volume had been nearly reached, whereas in the second case (T13, Fig. 11(b)) equilibrium had not been reached. It is evident that an interruption in a stage of loading does not affect the volumetric strain, because no discontinuity appears in the response. This fact could be viewed as highlighting the small influence that the frequency of cyclic loading has on the change of specific volume, since an interruption of one day is essentially one very slow cycle between two constantfrequency stages. However, a resting period can also give rise to ageing effects.

\section{RELATIONSHIP BETWEEN VOLUMETRIC STRAIN IN EQUILIBRIUM AND STATE PARAMETER}

The change of state parameter, $\Delta \psi$, has been determined at equilibrium for every applied $\beta$ value, as defined in Fig. 6 . In order to do this, all the cyclic loading stages in all the

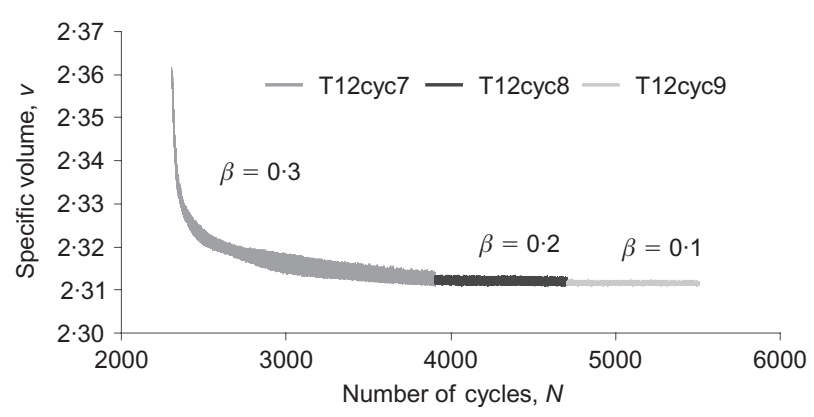

Fig. 10. The three final loading stages of test T12

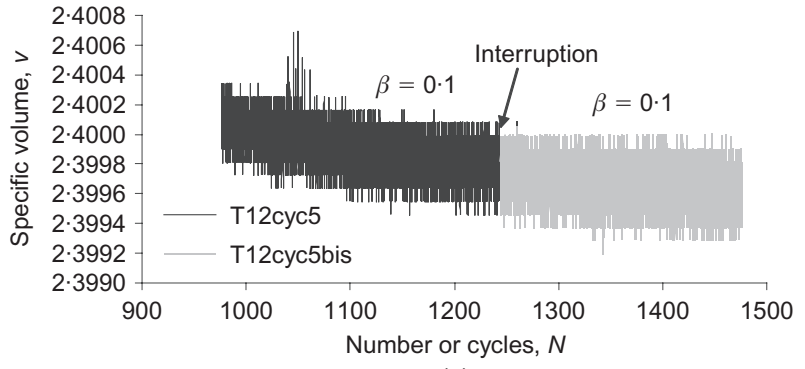

(a)

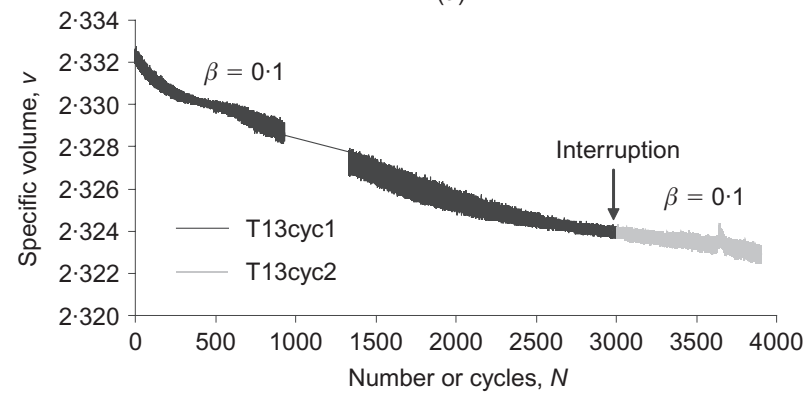

(b)

Fig. 11. Effect of an interruption between two stages of cyclic loading with same $\beta$ value: (a) sample T12, stages T12cyc5 and T12cyc5bis; (b) sample T13, stages T13cyc1 and T13cyc2

tests were reordered from the smallest to the largest $\beta$ value, as in Fig. 7. For each $\beta, \Delta \psi$ was then determined as the difference between the final specific volume after equilibrium and the initial specific volume under the isotropic condition before cycling. Fig. 12 shows the values of change of state parameter plotted against the initial state parameter for the eight tests, and for $\beta$ values of $0 \cdot 1,0 \cdot 2$ and $0 \cdot 3$. The results for $\beta=0.05$ are not given, since the values of $\Delta \psi$ were negligible in all cases for this amplitude of loading. From inspection of this figure it can be concluded that the change of state parameter, which is related to the volumetric strain, depends more or less linearly on the initial state parameter and the amplitude of the cyclic loading, $\beta$. It is also clear that, even for substantial negative values of $\psi_{0}$, rather than the dilation that would be expected for monotonic loading, the samples behave in a contractive manner for drained cyclic loading, although it is possible that, for very low $\psi_{0}$ values, dilative strains might be observed if the linear trends were maintained. It can be also concluded that the larger $\beta$ is, the larger is $\Delta \psi$, and the smaller the scatter in the linear regression through the experimental results. There is therefore no unique ultimate state line for drained cyclic loading that would be the equivalent of the CSL for monotonic loading. The only use, therefore, of the mono-

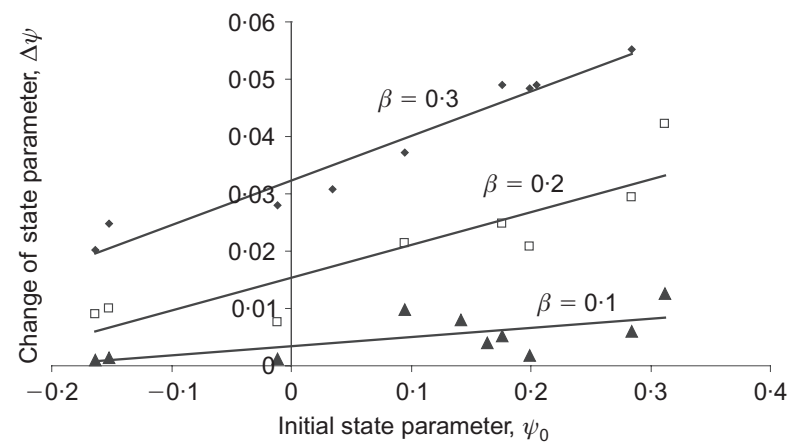

Fig. 12. Change of state parameter after equilibrium $(\boldsymbol{\beta}=\mathbf{0} \cdot \mathbf{1}, \mathbf{0} \cdot 2$ and $0 \cdot 3$ ) against initial state parameter for all tests 
tonic CSL for drained cyclic testing is in providing a reference line for the definition of the state parameters, but this is a function that the NCL could perform equally well.

Further research on very dense samples, with states far to the left of the CSL, and on both dense and loose samples under higher initial mean normal effective stresses would be useful in order to investigate further the relationships in Fig. 12. In drained cyclic loading the mean value of $p^{\prime}$ remains constant, and so the change of specific volume is equal to the change of state parameter. For other loading paths this would not be true, and so more tests on loose samples would be needed with different types of loading to establish completely a more general relationship between $\Delta \psi$ and $\psi_{0}$.

\section{PARTICLE BREAKAGE ANALYSIS}

The relative particle breakage $B_{\mathrm{r}}$, as defined by Hardin (1985), was determined at the end of four tests (T8, T10, $\mathrm{T} 11$ and T13). This calculation was made by comparing particle size distributions before and after the drained cyclic tests. In Fig. 13 these results are compared with the particle breakage of Dogs Bay sand under isotropic compression (NCL) and monotonic shearing to failure (CSL) (Coop \& Lee, 1993), and also with some data for the same sand cyclically loaded undrained, also until failure (Qadimi \& Coop, 2007). The results from the present study are broadly in agreement with the $B_{\mathrm{r}}$ values for samples monotonically loaded in isotropic compression, and also for those cyclically loaded until failure under undrained conditions. It can therefore be concluded that only small amounts of particle breakage occurred in these tests, almost irrespective of the number of cycles of loading applied. However, only modest numbers of cycles were applied here. It is possible that more significant breakage might occur for very much larger numbers, but since the volumetric strain is approaching equilibrium, and any breakage would be likely to be linked to continued volumetric strain, this seems unlikely.

\section{VOLUMETRIC STRAINS OF OVERCONSOLIDATED SAMPLES}

The last three stages of cyclic loading on sample T5 were made after subjecting it to isotropic unloading from a maximum $p^{\prime}$ of $500 \mathrm{kPa}$, and it was therefore overconsolidated. The results of these stages are given in Fig. 14. The initial state parameter at stages T5cyc10 and T5cyc11, under $p^{\prime}$ of $300 \mathrm{kPa}$, was 0.005 in both cases, and no change of state parameter was observed. The initial state parameter at stage T5cyc12, under $p^{\prime}$ of $100 \mathrm{kPa}$, was $-0 \cdot 316$, and a slight

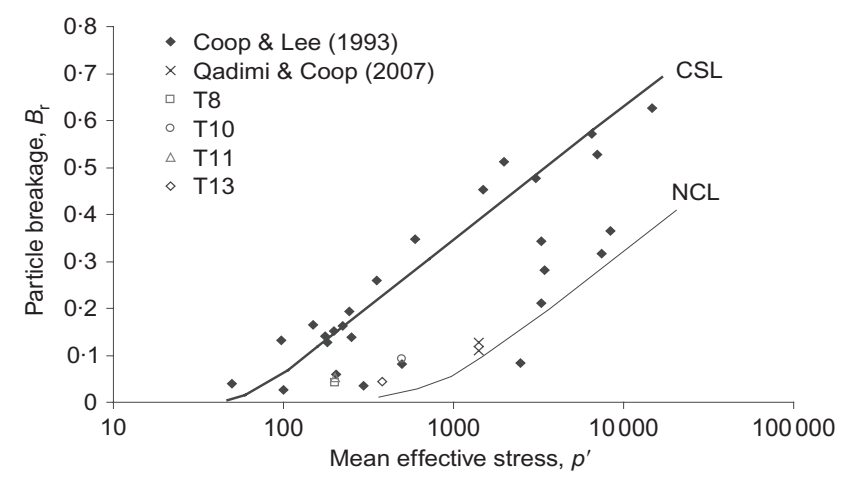

Fig. 13. Comparison between breakage data for monotonic loading (Coop \& Lee, 1993), undrained cyclic loading (Qadimi \& Coop, 2007) and drained cyclic loading (present study)

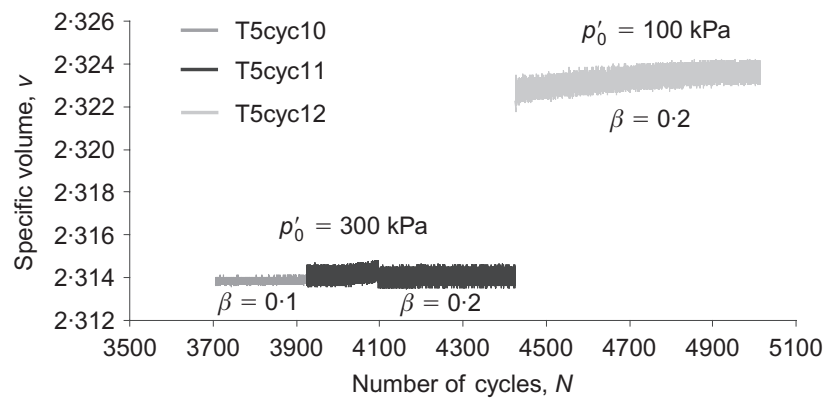

Fig. 14. Cyclic stages on sample $\mathrm{T} 5$ in an overconsolidated state

dilation was recorded in this case. It is clear that the behaviour is rather different from that of the other samples that were tested at the maximum $p^{\prime}$ to which they had been consolidated, with almost no permanent volumetric strain, and even a slight tendency to dilate in the last stage, when the sample was most overconsolidated (T5cyc12). More research is needed to establish relationships such as that in Fig. 12 for overconsolidated samples.

\section{CONCLUSIONS}

From the series of drained cyclic triaxial tests conducted on Dogs Bay sand presented in this paper, the following conclusions can be drawn.

(a) If several stages of loading with different amplitudes $(\beta)$ are applied to the sample, and equilibrium is not reached for any of these stages, the sand 'remembers' its previous loading history, and continuity can be found in the graph relating specific volume to the number of cycles if all the stages with the same $\beta$ are plotted together. The micromechanical explanation for this phenomenon is not known, but it means that the order of application of the stages of loading does not affect the final amount of volumetric strain. However, this continuity of response does not occur if equilibrium is reached for a higher $\beta$ value in the intermediate stage.

(b) For each amplitude of cyclic loading, $\beta$, the change of state parameter after equilibrium, $\Delta \psi$, increases linearly with the initial state parameter $\psi_{0}$. The larger the $\beta$, the smaller also is the scatter of the experimental results.

(c) No significant particle breakage has been observed after the tests conducted.

(d) A dramatic reduction of volumetric strains during drained cyclic loading is seen for overconsolidated samples, with a slight trend towards dilation at the highest overconsolidation reached.

(e) An interruption in a cyclic loading stage does not affect the final volumetric strain.

( $f$ ) More research on dense samples, on the dry side of the CSL, must be performed to characterise the drained cyclic behaviour of Dogs Bay sand completely.

\section{ACKNOWLEDGEMENTS}

This research would not have been possible without the assistance in carrying out the laboratory tests that was provided by Steve Ackerley, Alan Bolsher and Graham Keefe. The contribution of Dennis $\mathrm{Ng}$ is also kindly acknowledged. The experimental part of this investigation was carried out while the first author was an academic visitor at Imperial College, supported by the Spanish Ministry of Education and Science (postdoctoral grant EX-2006-1097). This financial support is gratefully appreciated. 


\section{NOTATION}

$B_{\mathrm{r}} \quad$ relative particle breakage

$D_{10}$ particle size for $10 \%$ passing in grading curve

$D_{50}$ particle size for $50 \%$ passing in grading curve

$D_{60}$ particle size for $60 \%$ passing in grading curve

$e_{\max }$ maximum voids ratio

$e_{\min }$ minimum voids ratio

$G_{\mathrm{s}} \quad$ specific gravity

$K_{0} \quad$ earth pressure coefficient

$M_{\mathrm{tc}} \quad$ CSL gradient in $q^{\prime}-p^{\prime}$ space $=\left(q^{\prime} / p^{\prime}\right)_{\mathrm{cs}}$

$p^{\prime}$ mean normal effective stress

$p_{0}^{\prime} \quad$ initial mean normal effective stress

$N$ intercept of NCL at $p^{\prime}=1 \mathrm{kPa}$ in $v-\ln p^{\prime}$ plane

$N$ number of cycles

$q$ deviatoric stress

$\Delta q$ amplitude of cyclic deviatoric stress

$q_{\max }$ maximum deviatoric stress

$q_{\min }$ minimum deviatoric stress

$U_{\mathrm{c}}$ uniformity coefficient, $=D_{60} / D_{10}$

$v$ specific volume

$v_{0}$ initial specific volume

$v_{\mathrm{f}}$ final specific volume

$\beta$ amplitude of cyclic loading ratio $\left(\Delta q / p_{0}^{\prime}\right)$

$\Gamma$ intercept of the CSL at $p^{\prime}=1 \mathrm{kPa}$ in $v-\ln p^{\prime}$ plane

$\kappa$ slope of swelling line in $v-\ln p^{\prime}$ plane

$\lambda$ slope of the isotropic NCL and CSL in $v-\ln p^{\prime}$ plane

$\phi_{\mathrm{c}}^{\prime}$ shear resistance angle at critical state

$\psi$ state parameter

$\Delta \psi \quad$ change of state parameter

$\psi_{0}$ initial state parameter

\section{REFERENCES}

Alarcón-Guzmán, A., Leonards, G. A. \& Chameau, J. L. (1988). Undrained monotonic and cyclic strength of sands. J. Geotech. Engng 114, No. 10, 1089-1109.

Arulmoli, K., Muraleetharan, K. K., Hossain, M. M. \& Fruth, L. S. (1992). VELACS laboratory testing program, soil data report, Report to the National Science Foundation, Washington, DC. Irvine, CA: The Earth Technology Corporation.

Atkinson, J. H. \& Bransby, P. L. (1978). The mechanics of soils. London: McGraw-Hill.

Atkinson, J. H. \& Evans, J. S. (1985). Discussion on 'The measurement of soil stiffness in the triaxial apparatus'. Géotechnique 35, No. 3, 378-380, http://dx.doi.org/10.1680/geot.1985.35.3.378.

Been, K. \& Jefferies, M. G. (1985). A state parameter for sands. Géotechnique 35, No. 2, 99-112, http://dx.doi.org/10.1680/geot. 1985.35.2.99.

Been, K., Jefferies, M. G. \& Hachey, J. (1991). The critical state of sands. Géotechnique 41, No. 3, 365-381, http://dx.doi.org/ 10.1680/geot.1991.41.3.365.

Castro, G. (1969). Liquefaction of sands. PhD thesis, Harvard University.

Chang, C. S. \& Whitman, R. V. (1988). Drained permanent deformation of sand due to cyclic loading. J. Geotech. Engng 114, No. 10, 1164-1180.

Coop, M. R. (1990). The mechanics of uncemented carbonate sands. Géotechnique 40, No. 4, 607-626, http://dx.doi.org/ 10.1680/geot.1990.40.4.607.

Coop, M. R. (1999). The influence of particle breakage and state on the behaviour of sands. Proc. 2nd Int. Workshop on Crushable Soils, Yamaguchi, Japan, pp. 19-57.

Coop, M. R. \& Lee, I. K. (1993). The behaviour of granular soils at elevated stresses. Proceedings of the C. P. Wroth Memorial Symposium: Predictive soil mechanics, London, pp. 186-198.

Cuccovillo, T. \& Coop, M. R. (1997). The measurement of local axial strains in triaxial tests using LVDTs. Géotechnique 47, No. 1, 167-171, http://dx.doi.org/10.1680/geot.1997.47.1.167.

Hardin, B. O. (1985). Crushing of soil particles. J. Geotech. Engng 111, No. 10, 1177-1192.
Houlsby, G. T., Evans, K. M. \& Sweeney, M. (1988). End bearing capacity of model piles in layered carbonate soils. Proceedings of the international conference on calcareous sediments, Perth, Vol. 1, pp. 209-214.

Jefferies, M. \& Been, K. (2000). Implications for critical state theory from isotropic compression of sand. Géotechnique 50, No. 4, 419-429, http://dx.doi.org/10.1680/geot.2000.50.4.419.

Jovicic, V. \& Coop, M. R. (1997). Stiffness of coarse grained soils at small strains. Géotechnique 47, No. 3, 545-561, http:// dx.doi.org/10.1680/geot.1997.47.3.545.

Kaggwa, W. S., Booker, J. R. \& Carter, J. P. (1991). Residual strains in calcareous sand due to irregular cyclic loading. J. Geotech. Engng 177, No. 2, 201-218.

Klotz, E. U. \& Coop, M. R. (2001). An investigation of the effect of soil state on the capacity of driven piles in sands. Géotechnique 51, No. 9, 733-751, http://dx.doi.org/10.1680/geot.2001. 51.9.733.

Klotz, E. U. \& Coop, M. R. (2002). On the identification of critical state lines for sands. ASTM Geotech. Test. J 25, No. 3, 289302.

Ko, H. Y. \& Scott, R. F. (1967). Deformation of sand in hydrostatic compression. J. Soil Mech. Found. Div. ASCE 93, No. SM3, 137-156.

Konrad, J. M. (1988). Interpretation of flat plate dilatometer tests in sands in terms of the state parameter. Géotechnique 38, No. 2, 263-277, http://dx.doi.org/10.1680/geot.1988.38.2.263.

Konrad, J. M. (1993). Undrained response of loosely compacted sands during monotonic and cyclic compression tests. Géotechnique 43, No. 1, 69-89, http://dx.doi.org/10.1680/geot.1993.43. 1.69.

Lee, K. L. \& Seed, H. B. (1967). Drained strength characteristics of sands, J. Soil Mech. Found. Div ASCE 93, No. SM6, 117-141.

Qadimi, A. (2005). The cyclic response of a carbonate sand through critical state soil mechanics. $\mathrm{PhD}$ thesis, Imperial College London.

Qadimi, A. \& Coop, M. R. (2007). The undrained cyclic behaviour of a carbonate sand. Géotechnique 57, No. 9, 739-750, http:// dx.doi.org/10.1680/geot.2007.57.9.739.

Schofield, A. N. \& Wroth, C. P. (1968). Critical state soil mechanics. London: McGraw-Hill.

Seed, H. B. \& Silver, M. L. (1972). Settlement of dry sands during earthquakes. J. Soil Mech. Found. Div. ASCE 98, No. 4, 381396.

Silver, M. \& Seed, H. B. (1971). Volume changes in sand during cyclic loadings. J. Soil Mech. Found. Div. ASCE 97, No. SM9, $1171-1182$.

Vaneekelen, H. \& Potts, D. M. (1978). Behaviour of Drammen clay under cyclic loading. Géotechnique 28, No 2, 173-196, http:// dx.doi.org/10.1680/geot.1978.28.2.173.

Verdugo, R. \& Ishihara, K. (1996). The steady state of sandy soils. Soils Found. 36, No. 2, 81-91.

Wichtmann, T. \& Triantafyllidis, Th. (2004a). Influence of a cyclic and dynamic loading history on dynamic properties of dry sand, part I: Cyclic and dynamic torsional prestraining. Soil Dynam. Earthquake Engng 24, No. 2, 127-147.

Wichtmann, T. \& Triantafyllidis, Th. (2004b). Influence of a cyclic and dynamic loading history on dynamic properties of dry sand, part II: Cyclic axial preloading. Soil Dynam. Earthquake Engng 24, No. 11, 789-803.

Wichtmann, T., Niemunis, A. \& Triantafyllidis, Th. (2005). Strain accumulation in sand due to cyclic loading: drained triaxial tests. Soil Dynam. Earthquake Engng 25, No. 12, 967979.

Wijewickreme, D., Sriskandakumar, S. \& Byrne, P. (2005). Cyclic loading response of loose air-pluviated Fraser River sand for validation of numerical models simulating centrifuge tests. Can. Geotech. J. 42, No. 2, 550-561.

Wood, D. M. (1990). Soil behaviour and critical state soil mechanics. Cambridge: Cambridge University Press.

Youd, T. L. (1972). Compaction of sands by repeated shear straining. J. Soil Mech. Found. Div. ASCE 98, No. SM7, 709-725. 